\title{
Histórias de Mulheres Catadoras: rompendo silêncios, edificando resistências, construindo novas escritas históricas
}

Luciana Codognoto da Silva*

Alzira Salete Menegat ${ }^{* *}$

\begin{abstract}
Resumo: Nos últimos anos, importantes produções teóricas têm sido realizadas no campo das ciências humanas, de forma a voltar olhares às práticas corporais e às corporalidades, uma vez que ele, o corpo, tem assumido novos significados como forte agenciador dos processos de subjetivação feminina. Entretanto, é preciso advertir que nem sempre foi assim. Pouco enxergadas na História, as mulheres estiveram relegadas aos papéis binários de mãe, esposa e vida privada, sendo pouco percebidas em suas particularidades. Sendo assim, esta pesquisa objetiva demonstrar como a História tratou os corpos - biológico e social - e os gêneros, de maneira a enfatizar os traços que se sobressaíram em determinados períodos históricos, produzindo o refazer de metodologias de análises que abrem caminhos para estudar a história das mulheres, em especial daquelas pertencentes à Associação de Reciclagem de Presidente Epitácio - ARPE. Localizada no interior do Estado de São Paulo, a Associação conta com um número considerável de mulheres associadas e em cargos de liderança. Para tanto, será utilizada a metodologia em história oral em paralelo às contribuições teóricas elencadas pela história cultural e os estudos das relações de gêneros. Percebe-se que este espaço de atuação profissional tem possibilitado às mulheres catadoras novas formas de experiência histórica e social, a partir do momento em que elas buscam subverter a um dado padrão historicamente construído sobre a feminilidade. É, pois, no âmbito do trabalho com os recicláveis que as mulheres catadoras, apesar das adversidades vivenciadas cotidianamente, se percebem enquanto portadoras de histórias a serem publicizadas pelos registros historiográficos.

Palavras-Chave: Mulheres na Reciclagem; Relações de Gêneros e de Poder; Resistências.
\end{abstract}

Abstract: In recent years, important theoretical productions have been made in the field of human sciences, so again looks to bodily practices and corporeality, since he, the body has taken on new meanings as strong bookie processes of female subjectivity. However, we must warn you that it was not always so. Shortly perceived in history, women have been relegated to the binary roles of mother, wife and privacy, with little perceived in their particularities. Thus, this research aims to show how history has treated the bodies - biological and social and genders, in order to emphasize the traits that have excelled in certain historical periods, producing the remake of analysis methodologies that open paths to study the history women, especially those belonging to the Recycling Association to the Presidente Epitácio - SP . Located within the State of São Paulo, the Association has a considerable number of women associates and in leadership positions. Therefore, the methodology of oral history parallel to the theoretical contributions listed by cultural history and studies of gender relations will be used. It is noticed that this professional workspace has enabled women waste pickers new forms of historical and social experience, from the moment they seek to subvert a given pattern historically built on femininity. It is therefore within the scope of work with the

\footnotetext{
${ }^{*}$ Mestre em História pela Universidade Federal da Grande Dourados - UFGD (2011). Doutoranda em Psicologia pelo Programa de Pós-Graduação em Psicologia da Universidade Estadual Paulista "Júlio de Mesquita Filho"UNESP/Assis. Endereço eletrônico: lupsico.codognoto@gmail.com.

** Doutora em Sociologia pela UNESP/Araraquara. Docente nos cursos de Pós-Graduação em História e Sociologia da Universidade Federal da Grande Dourados - UFGD.
} 
recyclable waste pickers that women, despite the hardships experienced daily, perceive themselves as people with stories to be publicized by the historiographical record.

Keywords: Women in Recycling; Relations Gender and Power; Resistances.

\section{Introdução}

Esta pesquisa tem por objetivo destacar importantes aspectos ligados aos âmbitos de trabalho e vida de mulheres sócias da ARPE - Associação de Reciclagem de Presidente Epitácio (SP) - formada por homens e, em sua grande maioria, por mulheres catadoras, que, desde o ano de 2003, passaram por uma nova experiência de organização e realização grupal das atividades de coleta e comercialização de resíduos sólidos no Município de Presidente Epitácio (SP). Optou-se por problematizar importantes pontos ligados à participação feminina na referida Associação, uma vez que ela se apresenta como um dos grupos de catadores, organizados coletivamente, mais estruturados da Região do Oeste Paulista, aliado ao fato de concentrar, em seu espaço de trabalho, um percentual significativo de mulheres associadas e em cargos de liderança.

Para tanto, algumas categorias de análise têm sido fundamentais no direcionamento deste estudo. No que se refere às relações de gêneros, elas são entendidas, nesta pesquisa, a partir das contribuições de Scott (1995), que as define como conjunto de características sociais, culturais, políticas, psicológicas, jurídicas e econômicas, atribuídas às pessoas de forma diferenciada, de acordo com o sexo. Ainda segundo a autora, o gênero é concebido enquanto categoria de análise historiográfica, como fenômeno relacional e como local onde se articulam as relações de poder. Assim, ao se fazer menção ao conceito de poder, dirige-se aos entendimentos sustentados por Foucault (1988), que escreve uma história que se conecta as políticas em nível micro, a qual ele denomina de Microfísica, local onde se institui um poder in lócus, complexo e difuso que propicia o estabelecimento e o agir das representações.

Há, também, que se destacar o estudo das relações entre história e memória. Nesta pesquisa, ele será realizado mediante as contribuições teóricas advindas de Halbwachs (2004) e Pollak (1989). Para os referidos autores, a memória mostra-se associada ao grupo social no qual o sujeito pertence, espaço onde a linguagem encontra posição privilegiada. Em suma, a memória perpassa o plano individual, carregando traços históricos, culturais e políticos de diferentes grupos e experiências sociais vividas cotidianamente pelos sujeitos, de forma a transparecer traços de uma coletividade. 
Tendo em vista estes aspectos, inicia-se o caminhar dialógico desta pesquisa salientando, primeiramente, a forma pela qual a História tratou os corpos - biológicos e sociais - das mulheres e como tais aspectos mostraram-se repercutidos nos debates acadêmicos e na própria escrita da História. Em um segundo momento, destaca-se a metodologia utilizada nesta pesquisa, a história oral em paralelo à história do tempo presente, e, por fim, será problematizada a presença de uma memória coletiva feminina, construída e evocada pelas mulheres da Associação de Reciclagem de Presidente Epitácio, enquanto importante forma de resistência, lutas e perspectivas de dias melhores e de vidas mais dignas.

\section{A História das Mulheres e os Estudos de Gêneros: revisitando debates}

Durante muito tempo, os papéis representados pelas elites do poder, da fortuna e da cultura, bem como a história dinástica, política, econômica e religiosa foram temas relevantes de abordagem e de pesquisas na historiografia, conforme evidenciaram os estudos de Burke (1992) e Le Goff (2002). Escrita fundamentalmente por homens, a narrativa histórica tradicional se absteve de incorporar às mulheres em suas preocupações e de dar vozes às diferentes experiências vividas por elas. Este silêncio marcou, por longos anos, a ausência das mulheres em importantes registros históricos. Embora este silêncio feminino tenha caracterizado grande parte da historiografia, é importante destacar que as mulheres sempre tiveram suas histórias.

Em contraponto à visão hegemônica de uma ciência histórica baseada em grandes feitos políticos, econômicos e religiosos, surgiu um novo modelo, uma forma de redefinição da narrativa histórica, assim denominado de História Cultural. A partir desta nova forma de narrativa histórica, a História, segundo Burke (2005), deixou de ser uma ciência preocupada exclusivamente com os meandros políticos, para assumir também a questão social e cultural e a reconhecer nela os diversos poderes que a engendra. É nesse espaço gerado pela História Cultural que o Feminismo e as pesquisas sobre as relações de gêneros buscaram alterar a exclusiva universalidade do homem como sujeito da História, dando início às problematizações sobre pessoas e grupos marginalizados tanto nos discursos cotidianos quanto nos debates acadêmicos.

Consideradas, durante muito tempo, apenas na dimensão privada como mães, responsáveis pela educação dos filhos e dos aspectos ligados ao lar, as mulheres foram esquecidas como integrantes do tecido social, ao serem assim imaginadas e representadas, em 
vez de contadas e, sobretudo problematizadas pela História Tradicional. E, mesmo, quando existiam publicações acerca do feminino: "ignorava-se quase sempre o que as mulheres pensavam a respeito, como elas as viam ou sentiam" (Perrot, 2008: p.22).

Ser mãe, esposa e dona de casa era considerado o destino natural das mulheres. $\mathrm{Na}$ ideologia dos anos dourados, ocorrida por volta da década de 1950, as ideias de maternidade, casamento e dedicação ao lar faziam parte do que consistia ser a essência feminina. Neste período, a mulher ideal era definida a partir dos papéis tradicionais de ocupação doméstica e de cuidado aos filhos, conforme apontam Del Priore e Pinsky:

A vocação prioritária da maternidade e a vida doméstica seriam marcas da feminilidade, enquanto a iniciativa, a participação no mercado de trabalho, a força e o espírito de aventura definiam a masculinidade. A mulher que não seguisse seus caminhos estaria indo contra a natureza, não poderia ser realmente feliz ou fazer com que outras pessoas fossem felizes (Del Priore e Pinsky, 2006: p. 609).

Este fato começou a apresentar importantes e visíveis rupturas a partir da disseminação dos estudos e pesquisas relacionados aos debates das relações de gêneros e de poder, engendrados pelo Movimento Feminista de 1960, conforme evidenciaram as análises de Saffioti (1976). Assim, na década subsequente, as mulheres cientistas passaram a estudar e a escrever sistematicamente sobre o universo feminino no Brasil. Estes estudos conquistaram espaço nas universidades, ao enfocar o tema trabalho e ao ter como primeiro alvo de análise as mulheres trabalhadoras e carentes. Neste momento, as pesquisas acadêmicas estavam voltadas às situações vividas pelas mulheres nos diferentes espaços e situações de trabalho, como a existência das duplas jornadas, os baixos salários pagos a elas e a inferiorização delas em cargos de chefias.

Os anos 1980 foram marcados pela tentativa de ampliação dos debates anteriormente vigentes. Passou-se a trabalhar com o termo relações de gêneros, ao invés de relações entre os sexos. Segundo Massi (1992), foi necessário desbiologizar a noção de sexo e integrá-la nas questões sociais. A partir de então, as mulheres passaram a ser percebidas não mais em uma rede integrada à posição binária dos sexos, mas, dos meandros políticos que envolvem as relações de gêneros, social e historicamente construídas.

Segundo Soihet e Matos (2003), a categoria gêneros, inicialmente, foi utilizada pelas feministas americanas, preocupadas em refutar o determinismo biológico, inevitavelmente expresso em termos de sexo ou de diferença sexual. Já para Scott (1995), o termo gêneros surgiu na tentativa de questionar a construção ou a suposição de uma identidade preexistente 
das mulheres, demarcada a partir dos traços biológicos e universais, o que contribuiu para se estabelecer significados particulares e, ao mesmo tempo, dúbio a homens e mulheres na sociedade e na forma como elas foram retratadas historicamente. Tais aspectos trouxeram à tona importantes debates sobre o modo e a necessidade de se articular os gêneros como categoria de análise na historiografia, como local onde se articulam relações de poder e enquanto construção social dos sexos. Logo, em outro momento, Scott adverte que:

A história das mulheres, sugerindo que ela faz uma modificação da 'história', investiga o modo como o significado daquele termo geral foi estabelecido. Questiona a prioridade relativa dada à 'história do homem', em oposição à 'história da mulher', expondo a hierarquia implícita em muitos relatos históricos. E, mais fundamentalmente, desafia tanto a competência de qualquer reivindicação da história de fazer um relato completo quanto à perfeição e à presença intrínseca do objeto da história o Homem universal (Scott, 1992: p. 78).

Assim, ao se realizar análises críticas em torno das formas pelas quais as mulheres foram retratadas ao longo dos tempos e em diferentes contextos sociais, se verá, de um lado, a ausência delas em importantes registros históricos e, de outro, a presença marcante de uma identidade feminina instituída, pautada na biologia dos corpos e nos binarismos e estabelecida segundo o sistema sexo/gênero/desejo/práticas sexuais, proposto por Butler (2003), em consonância com padrões heterossexistas, patriarcais, falocêntricos e reprodutivos.

Em síntese, é importante destacar que ambas as leituras sobre as mulheres - centradas tanto na invisibilidade quanto nos binarismos - denotam sinais latentes e visíveis de relações de poder, segundo bem salientou Foucault (1988). Entretanto, como bem adverte este autor, onde existe o poder, existe, paralelamente, a resistência. Logo, são as resistências a dadas normas de feminilidade que esta pesquisa intenta problematizar, mostrando que as mulheres inseridas no contexto de trabalho com os recicláveis se apresentam como sujeitos múltiplos e permeados pela ação das resistências a um dado modelo/padrão de feminilidade heterossexual, branco, classe média, escolaridade completa e, muitas vezes, inserido no âmbito do trabalho remunerado considerado cultural e socialmente, ora como masculino, ora como desprestigiado, por estar ligado ao serviço braçal e não apenas ao intelectual.

O que se evidencia através das análises de Butler (2003), que, por sua vez, é orientada por Foucault (1988), é que as ações exercidas pelo poder trazem em si os contra-poderes, ou seja, resistências que mostram possibilidades de outras existências, que ampliam e apontam que os corpos não se restringem às submissões esperadas. Em suma, para Butler (2003), o 
termo mulher se apresenta como problemático, até mesmo dentro do próprio Feminismo, na medida em que tem contribuído para o estabelecimento e a essencialização de uma determinada forma de ser mulher, o que, consequentemente, tem colaborado para deixar à margem as diferentes vozes, experiências e processos de subjetivação de muitas delas. Assim, como bem adverte esta autora, se fosse definir o que é uma mulher, certamente o que for dito, não dirá tudo o que essa mulher poderá ser.

Logo, pode-se pensar em diferentes mulheres nesta pesquisa, as quais intentam romper com a lógica binária dos sexos, ao apontar novas e possíveis formas de serem mulheres no contexto da lógica capitalista de produção e de consumo e ao demonstrar que seus corpos, outrora, considerados dóceis e frágeis, se apresentam, agora, fortes em termos psíquicos e físicos para o trabalho diário com os recicláveis. Paralelamente a estes questionamentos, há que se considerar que a redefinição dos papéis sociais de gêneros desponta como questão central nas discussões suscitadas pelo lugar que o corpo feminino tem ocupado e sido percebido em diferentes momentos históricos. Diante disso, surgem importantes questionamentos: Qual tem sido o papel, dado aos corpos femininos, na construção social do trabalho? E, em que medida, eles tem transitado da invisibilidade à contemplação da narrativa histórica das mulheres, em especial das mulheres sócias da Associação de Reciclagem de Presidente Epitácio?

\section{Metodologia}

A história do tempo presente será uma das principais vias para se problematizar importantes pontos suscitados durante esta pesquisa. Recorre-se a ela por se tratar de um tempo mais recente de análise, em que as pessoas e o contexto envolvidos estão ainda atuantes. Assim, no campo da História, serão realizados levantamentos de trabalhos e pesquisas que primam olhares aos estudos de gêneros, com especial destaque às contribuições teóricas elencadas por Scott (1992/1995), além de estudos voltados à História Cultural, enfatizando as formas pelas quais foram construídas as narrativas femininas, até então, invisibilizadas no fazer histórico.

O recurso à história oral será utilizado não somente pela insuficiência de fontes escritas ou de outros registros documentais, mas pela perspectiva mais geral adotada neste estudo. O desenvolvimento desta metodologia permitiu a mudança de enfoque nas pesquisas históricas, ao romper com visão rígida da objetividade do fato histórico e ao oferecer novas 
possibilidades e novos olhares às diversas maneiras de viver de diferentes pessoas e grupos poucos publicizados pela História. Nesta perspectiva, destaca a utilização da história oral enquanto fonte primária desta pesquisa, abrangendo perguntas abertas e semiestruturadas, dirigidas às mulheres sócias da Associação de Reciclagem de Presidente Epitácio.

A ideia de ampliar olhares sobre a história das mulheres catadoras se dá mediante a problematização de como se estabelecem as práticas diárias femininas nas conjunturas da vida privada e do trabalho local com os recicláveis. Na referida Associação, observou-se um percentual significativo de mulheres, correspondendo ao número de 33 (trinta e três), ou seja, 75\% dos 44 (quarenta e quatro) sócios/as que se fizeram presentes durante o momento de pesquisa na Associação, que abrangeu o período de janeiro de 2009 a janeiro de 2011. Tratase de mulheres pobres, muitas delas, provedoras ou coprovedoras de família e, em sua grande maioria, provindas das raças/cor negra e parda, que buscam no trabalho da Associação obter o sustento financeiro e a possibilidade de participação no mundo do trabalho não restrito ao lar.

Nos depoimentos externados, serão percebidos traços de uma memória coletiva, evocada e contada pelas catadoras como tempo essencial de criticidade e resistência vivido pela Associação de Reciclagem de Presidente Epitácio. Tais aspectos se transformaram em lembranças que reuniram aspectos objetivos de um contexto mais amplo, denominado pela História de "Memórias Coletivas". A partir disso, recorreu-se às contribuições de Pollak (1989) como meio de análise não somente dos contentos manifestos da linguagem, mas, sobretudo dos latentes que se fizeram presentes durante muitos momentos das entrevistas, visíveis tanto nas repetições de palavras, quanto na externalização de sentimentos por parte das depoentes.

Durante toda a pesquisa, houve a preocupação em se considerar apenas alguns aspectos que caracterizam as mulheres da Associação de Reciclagem de Presidente Epitácio, como forma de preservar as suas identidades e as suas histórias de vida. Assim, as depoentes serão evidenciadas pelas iniciais de seus nomes, idade, número de filhos/as e posição que ocupam dentro da Associação da qual fazem parte. Quanto ao tratamento dado às entrevistas, estas foram realizadas mediante a utilização do gravador de áudio, seguido do pedido de autorização das depoentes, o que proporcionou, simultaneamente, maior liberdade de expressão das pessoas entrevistadas, quanto à coleta de informações necessárias ao que se pretende analisar com este estudo.

\section{Resultado e Discussões}


A seguir, serão apresentados importantes aspectos ligados à análise dos relatos de histórias de vida das mulheres catadoras, entrevistadas nesta pesquisa. Tais relatos foram realizados mediante o recurso da metodologia em história oral e serão problematizados a luz das discussões teóricas que primam pelos estudos das relações de gênero, da história das mulheres e das analogias envolvendo história e memória.

\section{O Trabalho com os Recicláveis: memórias de mulheres catadoras}

Nos anos de 1990, assistiu-se no Brasil um elevado índice de desemprego, o qual acarretou profundas mudanças nas formas de trabalho, marcadas pelo crescente número de empregos informais, sem registro em carteira e instabilidade financeira e temporal dos/as trabalhadores/as. Neste mesmo período, a mundialização do capital emitiu efeitos complexos e contraditórios ao afetar desigualmente homens e mulheres, conforme ressaltam os estudos de Hirata (1998).

$\mathrm{Na}$ América Latina, particularmente após a reestruturação produtiva e a presença neoliberal, o fator desemprego passou a ser ainda mais acentuado. A precarização não ocorreu somente em relação à força de trabalho feminina, pois quando se analisam os dados apontados nas pesquisas de Bruschini e Lombardi (2002), verifica-se que as alterações no âmbito da vida profissional também atingiram os homens trabalhadores, ainda que de forma menos intensa.

A tendência à feminização do trabalho e sua acentuada precarização continua a se manter atuante no Brasil durante este século. Neste cenário, a atividade das mulheres catadoras surge como alternativa frente ao estado de desemprego e a falta de opções de ingresso no mercado de trabalho formal, conforme atestam os relatos das entrevistadas durante esta pesquisa. Este fato corrobora com a ideia de que a falta de perspectivas e qualificação profissional têm proporcionado o direcionamento de homens e, sobretudo de mulheres para as atividades de manuseio de resíduos sólidos, como forma de gerir sobrevivências para si e para seus familiares.

Neste contexto, Antunes (1995) assinala que a precariedade do trabalho refere-se à atividade mal remunerada e pouco reconhecida pelos aspectos legais e trabalhistas, estando ela vinculada à instabilidade de emprego e à restrição de direitos sociais dos trabalhadores/as. Considerando estes aspectos, faz-se importante salientar que a Associação de Reciclagem de Presidente Epitácio passou por um importante momento de crise financeira durante os anos de 
2008 e 2009, quando os rendimentos alcançaram uma média de duzentos reais por associada/o, a cada quarenta dias de trabalho. Estes fatores colaboraram para o estabelecimento de uma memória coletiva do grupo de mulheres da Associação, evocada e contada por elas como importante marco de dificuldade e também de superação da crise financeira.

Nas declarações externadas pelas entrevistadas, observou-se que o momento de crise envolveu a todas elas, produzindo lembranças comuns, o que remete pensar em trabalhos mais recentes, que se debruçam no entendimento das relações entre história e memória. Nesta pesquisa, os conceitos e as aplicações sobre memória coletiva são entendidos a partir das contribuições de Halbwachs (2004) e Pollak (1989).

A questão central deste conceito na obra de Halbwachs (2004) consiste na afirmação de que a memória individual existe sempre a partir de uma memória coletiva, posto que todas as lembranças são constituídas no interior de um grupo. Para o autor, este fato é o que garante a coesão no grupo, esta unidade coletiva, concebida como espaço de conflitos e influências entre uns e outros. Assim, para o autor:

A memória individual, construída a partir das referências e lembranças próprias do grupo, refere- se, portanto, a 'um ponto de vista sobre a memória coletiva'. Olhar este, que deve sempre ser analisado considerandose o lugar ocupado pelo sujeito no interior do grupo e das relações mantidas com outros meios (Halbwachs, 2004: p.55).

Portanto, a memória apoia-se sobre o passado vivido. Em Halbwachs (2004), ela é compreendida como a sucessão de acontecimentos marcantes nas experiências de pessoas e grupos, ocorrida de forma contínua e concebida a partir de pluralidades, assim denominada de memórias coletivas. Nesta pesquisa, tal memória mostra-se ligada ao período de crise financeira vivenciada de maneira global pelo mercado da reciclagem, acontecimento que obteve repercussão especial no trabalho desenvolvido pela Associação de Reciclagem de Presidente Epitácio, levando à queda dos rendimentos dos sócios/as. Durante aquele período, a Associação registrou somente a presença feminina nos diversos trabalhos, o que, nas palavras de uma das entrevistadas representou: "Somos guerreiras. A gente segura mais o trem do que os homens" (D.G.G.M, 26 anos. Sócia da Associação de Reciclagem de Presidente Epitácio. Entrevista realizada em 08 de março de 2010).

O estabelecimento da memória coletiva do grupo feminino mostrou-se intimamente vinculado ao fator econômico. Com a queda nos rendimentos e, consequentemente, a saída 
dos homens da Associação, as mulheres passaram a assumir todas as funções de manuseio dos recicláveis. A partir daquele momento, elas passaram a se reconhecerem fortes, não somente em relação ao fator físico do trabalho, mas, sobretudo, em relação às práticas psicossociais e históricas ligadas à atividade precarizante e mal remunerada de coleta e comercialização dos recicláveis. Estes aspectos foram evidenciados em outros momentos das entrevistas, em especial quando as sócias utilizavam palavras e/ou frases, como: "guerreiras"; "segurar o trem"; "é melhor pingar do que secar", entendidas como slogans e que remetem às expressões de força coletiva feminina, organizada em formato de estratégia para permanecerem em tempos de crises e buscarem saídas para a situação de dificuldade de cunho financeiro na Associação.

Destarte, dentre os motivos que colaboraram para a manutenção das mulheres na Associação, principalmente durante os momentos mais críticos, estava a necessidade de sustento financeiro da família, em especial dos filhos/as, conforme relatou uma das entrevistadas:

A necessidade é igual dentro de casa, mas a mulher ela pensa muito nos filhos [...] Tiveram homens que ficaram com a gente no período bom, quando a gente estava ganhando bem e depois eles não conseguiram, não resistiram, saíram. E depois eles viram que lá fora também estava difícil, pediram para voltar. Mas o que leva a mulher a ficar? São a família, os filhos. A gente tem uma maioria das mulheres aqui que pensam muito nos filhos [...] Eu não tinha como falar para vocês ficarem na Associação e passarem fome junto comigo e com a líder de atividades, mas dizíamos: vamos segurar e tentar ficar para poder levantar a Associação (E.H.P, 33 anos. Sócia/Presidente da Associação de Reciclagem de Presidente Epitácio. Entrevista realizada em 08 de outubro de 2010).

Logo, é possível afirmar que as mulheres da referida Associação se submeteram mais a atuação em empregos precários do que os homens, também sócios. Em outras palavras, as oportunidades de emprego oferecidas às mulheres não foram, naquele período, suficientes para absorver o mercado de trabalho formal no município, restando a elas, atividades de menor prestígio social e remuneração salarial, mas que se tornaram necessárias ao sustento financeiro de si e de suas famílias.

Neste contexto, a memória coletiva se apresentou como um olhar voltado ao passado de dificuldades e, o outro, ao tempo presente de superações femininas, uma vez que as mulheres externaram em seus relatos os problemas e as limitações financeiras e sociais que marcaram o período de crise financeira em seu espaço de trabalho. Segundo Pollak (1989), estas memórias, até então marginalizadas, abrem novas possibilidades e caminhos nos debates 
que primam pela história oral. Para ele, não se trata de lidar somente com os fatos sociais, mas de analisar como eles são solidificados e dotados de certa duração e estabilidade histórica. Neste estudo, a durabilidade e a estabilidade da memória feminina registram-se enquanto visão positiva apresentada e dirigida às mulheres durante o período percebido como marcante na trajetória de trabalho da Associação da qual elas fazem parte, conforme se pode observar no relato de uma das sócias:

Teve um tempo que não teve nenhum homem na Associação. Por quê? Porque eles chegam em casa, tem a família, a mulher está dentro de casa e ele chega com duzentos reais para poder pagar aluguel, água, ele não resiste à pressão. As mulheres que ficaram na Associação naquele período, eu dizia: Está aqui o dinheiro, vai dar duzentos reais. E elas diziam: antes pingar do que secar! Eu tenho três filhos em casa; a outra, é avó de família: tenho que manter a minha filha que está grávida dentro de casa, não tem como trabalhar, tenho mais três netos e se eu não tivesse os duzentos? Então, o homem não resiste tanto à pressão de chegar em casa e ver água pra pagar, aluguel e a mulher já pega aquele dinheiro e segura àquela pressão e tenta barrar as outras situações, até melhorar aquela situação. Como as mulheres são fortes, até no trabalho, para fazer cargas em 5 mulheres com 350 quilos; de elas segurarem a pressão e acharem que duzentos reais ainda dão para dar de comer aos filhos! (E.H.P, 33 anos. Sócia/Presidente da Associação de Reciclagem de Presidente Epitácio. Entrevista realizada em 08 de outubro de 2010).

A memória, como produto social e fruto de um sistema inscrito sobre determinadas características ou fatos sociais, espaciais e temporais, constitui-se nas relações entre pessoas que compartilham ou assimilam informações passadas e que se perpetuam ao longo do tempo. $\mathrm{Na}$ narrativa da entrevistada, a lembrança do tempo de dificuldades passou a ser evocada como sinônimo de força feminina, de modo a se apresentar como deslocamento de valores, haja vista que é a partir dos sinais da precariedade do trabalho que as mulheres catadoras se reconheceram sozinhas e, simultaneamente, providas de forças para enfrentarem os obstáculos sociais e financeiros no trabalho com os recicláveis.

Ademais, é importante enfatizar que o registro da memória coletiva feminina não se mostrou estritamente vinculado à questão financeira ou de classe. As relações de gêneros atuaram nesse contexto de maneira intensa, uma vez que, nas falas de muitas entrevistadas, os homens não resistiram à pressão de se manterem na Associação durante o período de crise financeira, migrando para outros pólos de trabalhos considerados tipicamente masculinos no município, como a atuação profissional em empreiteiras e como guardas/vigias noturnos em estabelecimentos privados e públicos da região. 
Se, por um lado, as representações sobre as mulheres continuam atuantes em muitos contextos da sociedade, sejam eles ligados à esfera privada ou pública, de outro, há que se registrar que os homens, em menor escala, também carregam as marcas geradas por representações, na medida em que a construção cultural lhes confere o poder de referência e provisão financeira da família. Tais conceitos, apesar de contestados nesta pesquisa, se mantêm atuantes na sociedade, por sua vez, respondidos em muitas famílias brasileiras e, de maneira especial, ficaram refletidos neste estudo durante o período de crise financeira vivenciada pela Associação de Reciclagem de Presidente Epitácio.

Em outras palavras, as mulheres catadoras negaram a construção social que, ainda hoje, produz representações de fragilidade e docilidade como palavras sinônimas do feminino. Em contraponto, tais mulheres se mostraram fortes para o trabalho e prosseguimento das atividades na Associação da qual fazem parte; já os homens sócios se esconderam por de trás das representações de provedores, de forma a não permanecerem nesse setor de produção, quando melhores possibilidades de emprego passaram a surgir para eles no município.

Este fato se vê reforçado pelas questões sobre a segmentação do mercado de trabalho, que tem direcionado às mulheres, sobretudo pobres e negras, aos grupos de mão-de-obra secundária, caracterizados pela instabilidade, baixos salários, desqualificação profissional e invisibilidade social. A questão estrutural sobre os aspectos que fazem referência ao trabalho feminino, evidenciada em estudos mais recentes, como os de Saffioti (1976), têm possibilitado importantes problematizações sobre as formas históricas e culturais da divisão sexual do trabalho, de modo a fixá-las em termos de reprodução dos papéis sexuais, em desacordo aos de gêneros.

Se a intensificação da participação feminina no mercado profissional ainda não tem garantido às mulheres catadoras igualdade de inserção e qualidade de trabalho, conforme se observou em muitos momentos desta pesquisa, a luta cotidiana e ativa delas pela conquista de direitos que apontem para a reversão deste quadro pode traduzir-se no aumento da negociação de garantias relativas à busca pela igualdade de gêneros. Em suma, este espaço de atuação profissional, historicamente ocupado majoritariamente por homens, tem se tornado, gradualmente, território de maior representatividade feminina, de modo a tornar-se o principal meio de sustento financeiro das mulheres entrevistadas e das famílias a elas vinculadas.

Tais aspectos assinalaram importantes rupturas das marcas geradas pelas representações, que, por muito tempo, conferiram o ambiente doméstico e o cuidado dos/as filhos/as como atividades fundamentais voltadas aos sujeitos femininos. Ademais, o trabalho 
local na reciclagem, ao mesmo tempo em que tem permitido a estas mulheres maior participação na vida pública, ainda as têm envolvido nas esferas pautadas na divisão sexual do trabalho, uma vez que, foram constatados durante a pesquisa, os seus direcionamentos para a atividade com os recicláveis devido às escassas possibilidades de emprego, com melhores garantias de estabilidade e remuneração social, oferecidas em outros setores laborais do Município de Presidente Epitácio - SP.

Por fim, este espaço de trabalho, mesmo que, marginalizado em muitos contextos da sociedade, tem se apresentado como caminho para a mudança de vida de muitas mulheres, a partir do momento em que elas buscam, ainda hoje, romper com os paradigmas sexistas, que as destinaram exclusivamente ao privado do lar para adentrar ao espaço público de trabalho da Associação, transformando a matéria considerada morta e obsoleta e, concomitantemente, modificando e atribuindo novas funções e direções as suas vidas e as de seus familiares.

\section{Considerações Finais}

Ao longo desta pesquisa foram analisadas questões teóricas e práticas referentes ao cotidiano de trabalho e vida de mulheres sócias da Associação de Reciclagem de Presidente Epitácio - ARPE. O levantamento de dados foi realizado através da metodologia em história oral em paralelo com as discussões suscitadas pela História Cultural. Os estudos de gêneros também se fizeram imprescindíveis na análise de importantes pontos suscitados durante esta pesquisa. O primeiro deles fez referência à sua articulação com a categoria trabalho remunerado e ao âmbito privado do lar.

Estes aspectos possibilitaram afirmar que o espaço de trabalho na Associação de Reciclagem de Presidente Epitácio tem se apresentado como local de fronteira para as mulheres catadoras, delimitando tanto fatores positivos - possibilidade de sobrevivência, mediante a prática diária feminina no trabalho considerado honesto, e, a partir dele, a obtenção do sustento financeiro - quanto fatores negativos - condições inadequadas de trabalho, baixa remuneração salarial e estigma e invisibilidade social.

Á guisa de conclusão pode-se afirmar que, este espaço de atuação profissional, historicamente ocupado majoritariamente por homens, tem se tornado, gradualmente, território de maior representatividade feminina, de modo a tornar-se o principal meio de sustento financeiro das mulheres entrevistadas e das famílias a elas vinculadas. Com as atividades que desempenham, as mulheres catadoras estão ressignificando o conceito de 
trabalho, dando vida à matéria considerada, biológica e socialmente, morta e obsoleta, criando oportunidades sociais e melhores condições de vida para elas próprias e para os seus familiares.

\section{Referências Bibliográficas}

ANTUNES, Ricardo. Adeus ao Trabalho: ensaio sobre as metamorfoses e a centralidade do mundo do trabalho. Campinas: Cortez, 1995.

BRUSCHINI, Cristina; LOMBARDI, Maria Rosa. Instruídas e Trabalhadeiras: trabalho feminino no final do século XX. Cadernos Pagu: desafios da equidade. Campinas: Unicamp, v.17/18, 2002.

BURKE Peter. (Org). A Escrita da História: novas perspectivas. São Paulo: UNESP, 1992. O que é História Cultural? Rio de Janeiro: Jorge Zahar, 2005.

BUTLER, Judith. Problemas de Gênero: feminismo e subversão da identidade. Rio de Janeiro: Civilização Brasileira, 2003.

DEL PRIORE, Mary; PINSKY, Carla Bassanezi (Ogs). História das Mulheres no Brasil. São Paulo: Contexto, 2006.

FOUCAULT, Michel. Microfísica do Poder. Rio de Janeiro: Graal, 1988.

HIRATA, Helena. Reestruturação Produtiva e Relações de Gênero. Revista Latino-Americana de Estudos sobre o Trabalho, v.7, n. 4, 1998.

HALBWACHS, Maurice. A Memória Coletiva. São Paulo: Centauro, 2004.

LE GOFF, Jacques. A História Nova. São Paulo: Martins Fontes, 2002.

MASSI, Marina. Cotidiano e Imaginário. Rio de Janeiro: Imago, 1992.

PERROT, Michelle. Minha História das Mulheres. São Paulo: Contexto, 2008.

POLLAK, Michael. Memória, Esquecimento, Silêncio. Revista Estudos Históricos. Rio de Janeiro: FGV, v.2, n. $3,1989$.

SAFFIOTI, Heleith Iara Bongiovani. A Mulher na Sociedade de Classes: mito e realidade. Petrópolis: Vozes, 1976.

SCOTT, Joan. História das Mulheres. In: BURKE, Peter. (Org.). A Escrita da História. São Paulo: Novas Perspectivas/UNESP, 1992.

Gênero, uma categoria útil de análise histórica. Educação e Realidade. Porto Alegre: UFRGS, v.20, Jul/Dez. 1995.

SOIHET, Rachel; MATOS, Maria Izilda de (Org.). O Corpo Feminino em Debate. São Paulo: UNESP, 2003. 